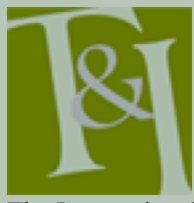

The International Journal for Translation \& Interpreting Research trans-int.org

\title{
Explicitation in Translation Studies: The journey of an elusive concept
}

\author{
Elisabet Titik Murtisari \\ Satya Wacana Christian University \\ etmurtisari@gmail.com
}

DOI: 10.12807/ti.108202.2016.a05

\begin{abstract}
Due to its pervasiveness, explicitation has received much attention in translation research. However, studies seem to have overlooked the basic underlying concepts of 'explicit' and 'implicit'. Moreover, these notions have been understood in various ways, making it difficult, for example, to compare research results on explicitation and describe the phenomenon. To better clarify the issue, this paper examines the commonly used concepts of 'explicit' and 'implicit' and how they have been applied in explicitation studies, beginning with the classic work of Vinay and Darbelnet. While the concept of explicitation is far from simple, few studies have devoted enough room to examine it.
\end{abstract}

Keywords: translation, explicitation, implicitation, explicitness, explicit, implicit

\section{Introduction}

Explicitation is generally defined as a shift in translation from what is implicit in the source text to what is explicit in the target text. Because of the pervasiveness of this textual phenomenon, there has been a great deal of research on explicitation. In spite of this, few studies have devoted enough room to the examination of the very notion of explicitation, particularly how it relates to the basic underlying complex of 'explicit' and 'implicit'. Moreover, these concepts have apparently been understood in various ways, making it difficult to compare research results and describe the phenomenon in a more comprehensive way (see, for example, Kamenická, 2007). The author has personally proposed an alternative framework based on Relevance Theory to deal with the issue (Murtisari, 2011, 2013), but more research is necessary to test its analytical power (or to refine it) and possibly find out if a more refined framework may better describe the phenomenon. To understand the crucial need for such research, it is paramount to consider the journey of the notion of explicitation and how the failure of defining the concepts of the 'explicit' and 'implicit' has made research less fruitful. With the above purpose in mind, this paper examines how the concepts of 'explicit' and 'implicit' have been applied in explicitation studies, beginning with the work of Vinay and Darbelnet (1958). After surveying the early notions of explicitation (chronologically, Vinay \& Darbelnet, 1958; Nida, 1964; and Blum-Kulka, 1986/2000), discussion will focus on research since the end of the 1980s, which includes work on implicitation (e.g., Séguinot, 1988; Øverås, 1998; Klaudy, 2004). The study will end with a review of several alternative frameworks, including the author's own proposal, and a statement of the need 
for further research. Much work remains to be done in order to pin down the elusive concept of explicitation.

\section{The explicit and the implicit}

Based on its dictionary meanings, in its day-to-day use the English word 'explicit' refers to the visibility, comprehensibility, or accessibility of something that has already been expressed (Murtisari, 2013). The word 'implicit', on the other hand, normally refers to indirect accessibility, whether by inference, its being contained by something else, or implication (Murtisari, 2013). The generic meanings of 'explicit' and 'implicit' have been adopted as terms in different areas of Linguistics, but they refer to different concepts. Since these concepts were discussed in a previous article on explicitation (Murtisari, 2013), they will only be addressed briefly here. The concepts of explicitness and implicitness used in explicitation research may be categorized into three types: encoded/inferred, textual, and a combination of the two.

\subsection{The encoded/inferred system of explicitness and implicitness}

\begin{tabular}{|l|l|}
\hline Explicit & Encoded \\
\hline Implicit & Inferred \\
\hline
\end{tabular}

Figure 1. Explicitness based on the traditional encoded/inferred meaning levels (Murtisari, 2013, p. 317)

The encoded/inferred approach is based on distinct levels of meaning. A piece of information is said to be "explicit" when it is encoded in linguistic forms (Carston, 2002; Sperber \& Wilson, 1986) and "implicit" when the meaning can only be recovered through inference. A theoretical basis for this distinction, commonly used in General Linguistics, seems to be lacking. It appears to be used only as an informal alternative to the encoded/inferred differentiation (C. Allen ${ }^{1}$, personal communication, April 3, 2009; Carston, 2002). The encoded/inferred system has also been criticized for being too simplistic to represent the explicit and the implicit, since the recovery of any communicated assumption, including that encoded in a linguistic form, requires an element of inference (Carston, 2002; Sperber \& Wilson, 1986).

\subsection{Textual/discourse-based explicitness}

Textual explicitness differs from the type of explicitness dealt with above, in that it is more a matter of a degree than just a category. It is often used in linguistic textual studies, such as discourse analysis. The degrees of explicitness of a particular language depend on factors such as encodedness, informativity, specificity, emphasis/focus and topicality in the information packaging. Explicitation based on textual explicitness will consist in a shift to a higher degree of encodedness, informatifity, specifity and so on. In spite of this, scholars have different ideas on what contributes to textual explicitness. Some researchers, for instance, even include typographical markers such as italics and boldface as forms of explicitness (Ädel, 2002).

\footnotetext{
${ }^{1}$ Linguistics researcher and former lecturer at the Australian National University (ANU). 


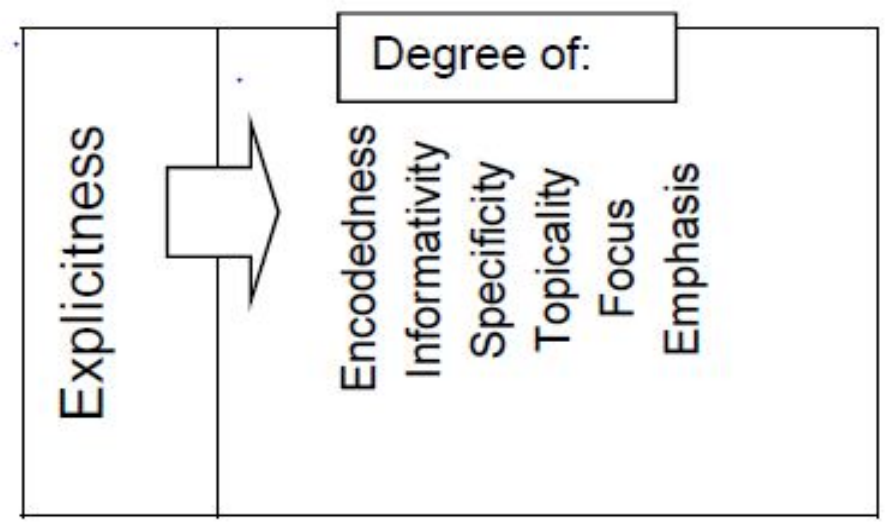

Figure 2. Textual/discourse-based explicitness (Murtisari, 2013, p. 318)

In discourse analysis, Schiffrin (1994/2003) explains that explicitness is a feature relating to the representation of referents. According to Schiffrin, explicitness is concerned with "presentation of information that actually enables [the hearer] to correctly identify a referent, i.e. the lexical clues that allow [the hearer] to single out whom (or what) [the speaker] intends to differentiate from other potential referents" (1994/2003, p. 199). Defined in this way, explicitness is relative since it is the listener who actually determines its degree, based on his/her point of view. What is explicit to one person may be perceived differently by another. While this reader-based notion of explicitness seems commonly applicable to day-to-day life, explicitation research definitely needs a framework that explains explicitness more objectively.

\subsection{Combined system of encoded/inferred and textual explicitness}

In discourse analysis (e.g. Schiffrin, 1994/2003), textual explicitness is often combined with the encoded/inferred distinction of explicitness and implicitness. Within such a system, textual explicitness occupies the encoded category of the meaning-level distinction.

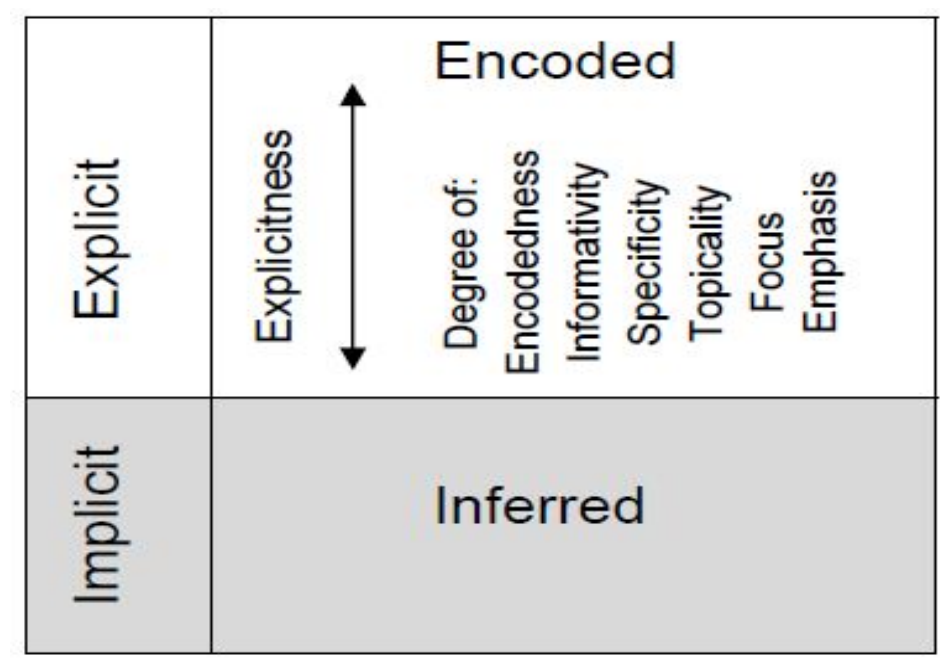

Figure 3. Explicitness based on textual explicitness and encoded/inferred distinction (Murtisari, 2013, p. 318) 
As shown in the figure above, what is inferred is automatically implicit and is bound to be more implicit than any encoded meaning. The encoded, on the other hand, lends itself to the explicit, but to a greater or lesser degree. Although this combination system is very helpful when dealing with static explicitness in discourse analysis, it seems unable to accommodate the dynamic characteristic of translation. The two systems of explicitness become incompatible when applied together to explain shifts from the SL to TL. While the meaning spelled out in explicitation may be more general than the source item it has replaced, what is more general cannot be more explicit within this combined system (Kamenická, 2007). This being the case, Kamenická concludes that the combined type has "limited validity"for explicitation research (2007, p. 48).

\section{Development of the "explicitation" concept in Translation Studies}

This section will cover the development of the explicitation concept in Translation Studies (TS) and how the different approaches to explicitness outlined in the previous section are utilized by different scholars, starting from Vinay and Darbelnet (1958) to Blum-Kulka (1986/2000).

\subsection{Vinay and Darbelnet (1958)}

The concept of explicitation seems to have been first introduced into TS by Vinay and Darbelnet in their influential work entitled Stylistique comparée du français et de l'anglais: Méthode de traduction (1958). The two scholars defined explicitation as a 'procédé qui consiste à introduire dans LA des précisions qui restent implicites dans $L D$, mais qui se dégagent du contexte ou de la situation" (1958, p.9), "a procedure that consists in introducing in the target language details that remain implicit in the source language, but become clear through the relevant context or situation" (the author's own translation, verified by Brian Nelson ${ }^{2}$, personal communication, 16 March 2016.

The French expression précisions may also suggest the notion of "clarity" because it is derived from the verb préciser, which means "to clarify', " to be more specific about", or "to state, to specify" (Collins English French Electronic Dictionary, 2005, n.p.). However, a closer examination of Vinay and Darbelnet's $(1958,1995)$ examples of explicitation reveals that they are all cases that result in a more specific/informative meaning in TL, not the spelling out of recoverable meaning that results in generalization. Furthermore, according to the scholars, the more informative meanings may be derived from linguistic and extra-linguistic contexts and may also include the cognitive context of the interlocutors, i.e. of writers, translators and readers of translations. Thus, Vinay and Darbelnet's explicitation also covers the spelling out of pragmatic meanings to cater to the readership. In their point of view, explicitation (as a gain) makes a sentence more "self-sufficient" by making the comprehension of it "less dependent on the context or the situation," which thereby "frees the reader from referring to either" $(1995, \mathrm{p}$. 70).

It can be concluded that Vinay and Darbelnet's (1958) original model of explicitation is based on a limited combination of meaning-level and textual types of explicitness. In their view, explicitation comes from contextually recoverable meanings. However, the two scholars seem to restrict it to shifts that endow the target text with more specific information, although this point is not precisely expressed in the book.

\footnotetext{
${ }^{2}$ Emeritus Professor in French Studies, Monash University, Australia.
} 


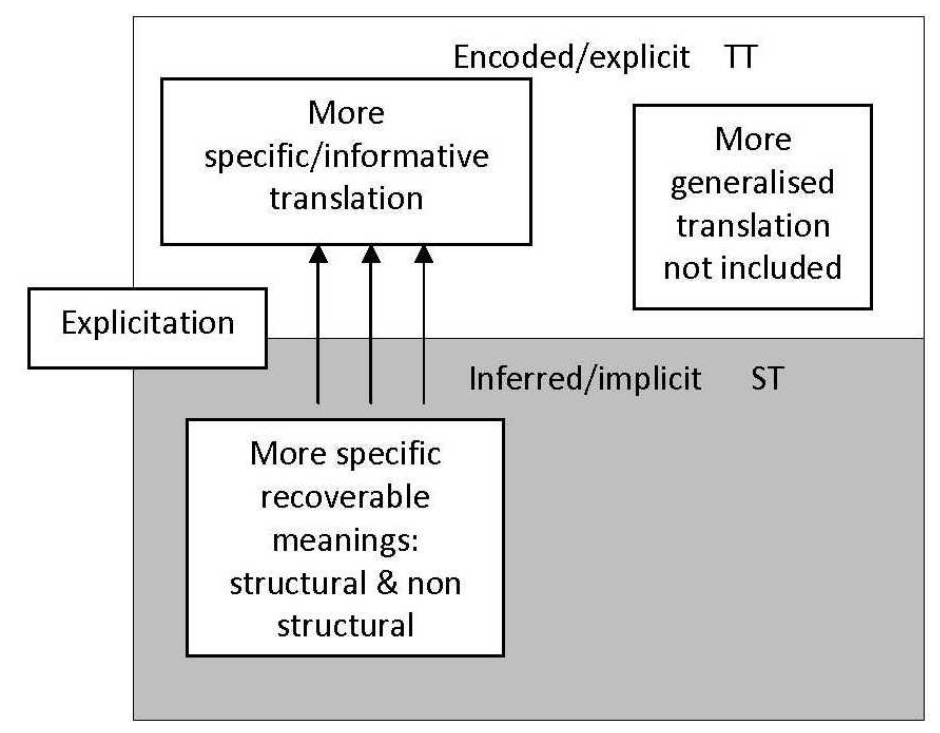

Figure 4. Vinay and Darbelnet's concept of explicitation (Murtisari 2011, p. 38)

It is important to note that Vinay and Darbelnet's definition of explicitation has a slightly but significantly different meaning in the English translation by Sager and Hamer (1995). The translators have rendered the definition as "a stylistic translation technique which consists of making explicit in the target language what remains implicit in the source language because it is apparent from either the context or the situation" $(1995$, p. 342). In this translation, the French phrase introduire dans LA des précisions qui restent implicites dans $L D$ ("introducing in the target language details that remain implicit in the target language") is replaced by "making explicit in the target language what remains implicit in the source language". Although this seems only slightly different, it has a critical implication; the English definition suggests that explicitation may also include shifts resulting in a more general expression than the corresponding ST, which is also common in translation. Unlike Vinay and Darbelnet's original concept, explicitness is here looked upon as a category of meaning (encoded-inferred distinction, as it is commonly understood).

\subsection{Eugene Nida}

Nida used the term 'addition' to refer to the incorporation of elements that "may legitimately be incorporated into a translation"(Toward a Science of Translating, 1964, p. 227), which is similar to the notion of explicitation. Like Vinay and Darbelnet with 'gain', Nida seems to have used the term 'addition' because the contemporary idea of fidelity was closely tied to the form of the ST. His additions are not "simple additions", but are restricted to information that is clearly recoverable from the text or context. These additions may be grammatical, such as filling out elliptical expressions, or use of classifiers and connectives to create "structural alteration" (p. 227). Nida also mentions "amplification from implicit to explicit status" as another kind of addition (p. 227). This type involves the explication of meaning derivable from context, which may be related to the text's socio-cultural context, in order to enhance readability or to avoid misunderstanding when there is ambiguity. In sum, like Vinay and Darbelnet (1958), Nida's explicitation-like concept is also based on a limited combination of meaning level and textual types of explicitness. 
While this shift has to be motivated by an appropriate interpretation of ST, the scholar only focuses on it as a gain.

\subsection{Blum-Kulka}

About two decades after Nida, Blum-Kulka (1986/2000) conducted what is often considered the first systematic study of explicitation. Unlike Vinay and Darbelnet and Nida, Blum-Kulka limits her study only to the increase of explicitness resulting from shifts of cohesiveness and coherence at the TT discourse level. Blum-Kulka does not define what she means by the term 'explicitness', but she seems to be more interested in the lexical increase that may result in 'redundancy' (hence textual explicitness).

Blum-Kulka proposes the so-called 'explicitation hypothesis', which she defines as "an observed cohesive explicitness from SL to TL texts regardless of the increase traceable to differences between the two linguistic and textual systems involved" (1986/2000, p. 300). ${ }^{3}$ According to her, (such) explicitation results from "the translation process itself", i.e. from "the process of interpretation performed by the translator on the source text"(p. 300). The scholar further claims that explicitation may well be a "universal strategy inherent" in the translation process (p. 302). However, it is not clear what Blum-Kulka means by explicitation as a strategy (Becher, 2010a), since she is more interested in the increase of textual explicitness resulting from translation shifts rather than how the translator employs them.

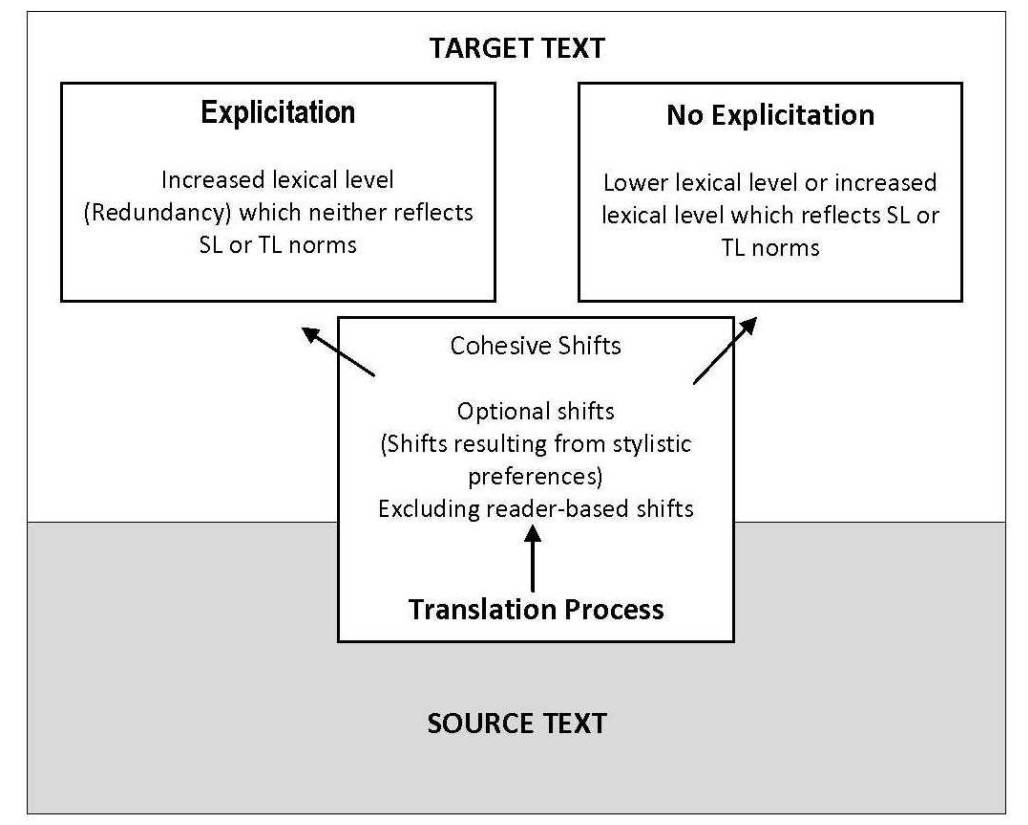

Figure 5. Blum-Kulka's concept of explicitation

To find out if there is explicitation of cohesion and coherence in translation, Blum-Kulka suggests that only 'optional' shifts should be considered as opposed to 'obligatory' ones (p. 312). Optional shifts are those "attributable to stylistic preferences", whereas obligatory shifts refer to those "dictated by the grammatical systems of the two languages" (p. 312). In addition to this, Blum-Kulka also states that the optional shifts considered for Explicitation Hypothesis should exclude "reader-based" information, which is

\footnotetext{
${ }^{3}$ Blum-Kulka also states that explicitation may "[go] beyond changes in cohesive forms" (1986/2000, p. 301). She does not, however, explore the case further, and thus has nothing to say on the extent of explicitation.
} 
added to cater to the target reader. One should instead focus on text-based shifts resulting from the translator's "diagnosis" of the source text (p. 309).

Since text-based shifts may also be "linked to well-known differences between linguistic systems" (p. 309), Blum-Kulka recommends the need for a "large-scale contrastive stylistic study" for validating her hypothesis. The stylistic information will be useful to examine the pattern(s) of the selected optional shifts, which may conform to the ST, the TT or neither. When the latter is the case, then explicitation has occurred in translation text. While this comparative method can be inferred from a very close reading of her article, Blum-Kulka does not explain it in a straightforward manner. It has therefore been interpreted in different ways in explicitation research.

\section{Research on explicitation since the end of the $1980 \mathrm{~s}$}

Research in the area of explicitation grew quite dramatically after BlumKulka's study. Since then, the focus has been on proving her hypothesis of the universality of explicitation while continuing to explore what qualifies as explicitation. Examples of such studies include those done by Séguinot (1988), Weissbrod (1992), Øverås (1998), and later by Olohan and Baker (2000), Klaudy (2004), Frankenberg-Gracia (2004), Puurtinen (2004), Pápai (2004), Hansen-Schirra, Neumann \& Steiner (2007), and Klaudy and Károly (2005). Most of these studies share a relatively similar interest, i.e. the universality of explicitation. Concepts of the phenomenon itself, however, vary from one researcher to another. These views differ little from earlier concepts except in application methods used in studying explicitation. Attempts have been made to address the conceptual issue, but none of the suggestions has been implemented in any significant way.

It is Vinay and Darbelnet's concept translated by Sager and Hamer (1995) that has been most commonly cited and used as a basis for major explicitation research from the end of the 1980s onwards (e.g. Olohan \& Baker, 2000; Øverås, 1998). As mentioned above, the translated definition is broader than the French original in that it may also include explicitation shifts resulting in more general information. Despite this difference, in 1990s interpretations of the English concept of explicitation tended to resemble the French version. Researchers still tend to see an increase of informativity and specificity as important features of explicitation. In Klaudy and Károly's (2003) research, for instance, specification is seen as an aspect of explicitation, while generalization is associated with implicitation. Similarly, Olohan and Baker (2000) see explicitation as the provision of "extra information" while using encoded/inferred explicitation as the basis of their explicitation research (as is shown by their definition of explicitation, i.e. "spelling out of information otherwise implicit in the source language" (p. 142)). In addition to this, Klaudy (1998) classifies explicitation into four groups, which seem to be a development of Blum-Kulka's work. It is important to note, however, that the two scholars' concepts of 'optional shifts' are different. Unlike Klaudy, Blum-Kulka does not see her (Blum-Kulka's) 'optional' shifts (and other shifts that merely lead to higher explicitness) as 'explicitation'. Klaudy (1998) proposes the following categories of explicitation:

1. Obligatory explicitation. This results from structural differences between SL and TL.

2. Optional explicitation. According to Klaudy, this type of explicitation is caused by "differences in text-building strategies [...] 
and stylistic preferences between languages" (Klaudy, 1998, p. 83). Such shifts are optional "in the sense that grammatically correct sentences can be constructed without their application in the target language, although the text as a whole will be clumsy and unnatural" (Klaudy, 1998, p. 83). This concept is more specific than BlumKuka's optional shifts, which only refer to those resulting from stylistic preferences.

3. Pragmatic explicitation. This is caused by differences in the culture and world knowledge of SL and TL members.

4. Translation-inherent explicitation. This "can be attributed to the nature of the translation process itself" (Klaudy, 1998, p. 83).

According to Englund Dimitrova (2005, p. 38), Klaudy's typology is difficult to apply because the categorizations come from different criteria and levels. While translation-inherent is a hypothetical type, the rest are based on linguistic realizations (p. 38). Englund Dimitrova also points out that pragmatic explicitations are a sub-category of optional explicitations.

The "mixed" intuitions on the notion of explicitation (e.g. as demonstrated by the use of Vinay and Darbelnet's English definition of explicitation while still clinging to other aspects that go with the original definition and the vagueness surrounding the explicitation hypothesis) has complicated explicitation research, especially in regard to concept development. In spite of this, little attention has been paid to this conceptual area. In searching for evidence for the Explicitation Hypothesis, the types/forms of explicitation have received the bulk of scholarly attention. Perhaps it is the lack of conceptual clarity that has led to a loss of focus.

Indeed the proliferation of various research methods with different theoretical implications in this area makes it difficult to compare results or to draw a larger picture of the phenomenon. In general, however, researchers can be categorized into three groups, i.e., those who tend to follow Vinay and Darblenet's translated concept of explicitation, those who tend to follow Blum-Kulka's notion, and those who try to combine these two approaches. Alternative frameworks have also been suggested, and these will be discussed in a separate section.

\subsection{Studies based on Vinay and Darbelnet's translated concept}

There are a number of studies which strictly follow Vinay and Darblenet's translated concept of explicitation, based on the encoded/inferred distinction for the explicit and implicit. These studies vary in the extent of their understanding of explicitation, but the phenomenon tends to be limited to the encoding of inferred meanings in the target language. In practice this would exclude non-lexical shifts, but they are restricted to linguistic units (normally in the form of words) that are added by the process of explicitation.

Studies belonging to this category include those conducted by Weissbrod (1992), Frankenberg-Gracia (2004), Englund Dimitrova (2005), HansenSchirra et al. (2007) and Becher (2010b). Weissbrod for instance, has studied translations of fiction from the 1960s to the 1970s (1992, p. 153). Following Vinay and Darbelnet (1995), Weissbrod (1992, p. 153) defines explicitation as "turning the implicit (in the source text) into the explicit (in the translation)". She does not specifically define what she means by 'explicit' and 'implicit', yet her examples show that they involve encoding and inference.

Englund Dimitrova (2005) is another scholar that seems to use Vinay and Darbelnet's translated concept. She examines the explicitation of implicit logical links in terms of 'process' (cognitive process in translating) and 'product' (the resulting translation). While she provides an in-depth review of 
studies on explicitation, there is no discussion on the underlying concepts of explicitness or on those of her own. Her explanation, however, suggests that explicitation refers to the "verbalization" of logical links that can be "inferred" from the ST's context (2005, p. 226). She is also more interested in the relationship of meaning between the ST and TT than on the shift of textual explicitness. On this basis, it is safe to conclude that she uses the encoded/inferred distinction of explicitness.

The study of Hansen-Schirra et al. (2007) also investigates explicitation in light of the traditional encoded/inferred notion. While the scholars believe that explicitation may occur at different levels of interpretation, including "high-level interpretations" by human interlocutors (hence, pragmatic) (2007, p. 243), their research focuses on "properties of encoding".

They exclude "simple" addition and omission because such changes do not imply any relationship between the source text (ST) and target text (TT) (2007, p. 244). They believe that explicitness and explicitation "operate differently and thus have to be analyzed in different ways" (2007, p. 262). For them, 'explicitation' is concerned with the ST and TT relationship, while "explicitness' of grammar and vocabulary is linked with "density" and "directness" (2007, p. 242).

Shifts of textual explicitness can also be seen in terms of a relationship by excluding meanings that are not generated from the source text. Therefore, the issue here should not be 'explicitation' and 'explicitness', but rather two different types of explicitation: one is based on meaning-level explicitness (the traditional notion), the other on textual explicitness. In spite of this, the effort of Hansen-Schirra et al. to discuss the conceptual aspects of explicitation is crucial in that it demonstrates their awareness of the real issues of explicitation. This is lacking in most other research projects in this subject area.

In addition to the study conducted by Hansen-Schirra et al., another research project that may be categorized in the group of studies under examination is Becher's (2010b), which calls for abandoning the translationinherent concept of explicitation in Blum-Kulka's hypothesis (Becher, 2010a). Becher's (2010b) purpose is to disconfirm Blum-Kulka's concept of translation-inherent explicitation. In spite of this, he basically follows Vinay and Darbelnet's translated concept of explicitation. This can be seen by his concept of explicitness, which is based on meaning levels, i.e. "the verbalization of information that the addressee would (most probably) be able to infer from the context, her world knowledge or from other inferential sources if it were not verbalized" (2010b, p. 2). Although this concept of explicitness is valid in the context of his investigation of the German adverb damit, Becher's understanding of inferability is debatable. This appears when he argues against what Kamenická $(2008$, p. 127) cites as a case of explicitation:

ST (English): Now, before you get upset listen to me.

TT (Czech): 'Now, before you get upset you must listen to me' (Back translation $\left.{ }^{4}\right)$

Becher refuses to call the above translation shift 'explicitation' because, in his words, "the existence of an addressee is part of the imperative's constructional meaning and thus does not need to be inferred" $(2010$, p. 6). This view, however, does not seem to be accurate. Even though the meaning 'you' may be a part of the imperative form, it is not verbally evident. Before figuring out that the subject is you, one would still need to infer from the

${ }^{4}$ Kamenická does not provide the Czech original in her explanation. 
context if the construction is an imperative and, if that is the case, if the subject does not refer to somebody, which may also be an implied subject of such a construction (Wilson, 2014).

The above studies are restricted to the examination of straightforward cases and therefore do not take issue with data in regard to their concept of explicitation. Becher's (2010b) case, however, demonstrates the need for a comprehensive framework for explicitation research to explain shifts that cannot be easily categorized as explicitation.

\subsection{Studies that tend to follow Blum-Kulka's concept}

Despite ongoing work with traditional approaches, Blum-Kulka's hypothesis became dominant after 1995. Yet considering Hansen-Schirra et al.'s (2007, p. 262) observation that textual explicitness "operate[s] differently" from encoded explicitness, should we separate explicitation based on textual explicitness entirely? Many studies of explicitation, mostly working with Blum-Kulka's hypothesis, tend to use both traditional and textual notions of explicitation in the same study in one way or another instead of following her concept of explicitation strictly. There are three types of studies: those using parallel texts (Øverås, 1998; Séguinot, 1998), comparable texts (e.g. Olohan \& Baker, 2000; Puurtinen, 2004), and research applying these two methods (Pápai, 2004).

Øverås (1998) has adopted Blum-Kulka's term of 'explicitation' for "[the] translation process where implicit, co-textually recoverable ST material is rendered explicit in TT" $(1998$, p. 4). She has also added specification as one category of explicitation because it contributes to increased explicitness. However, this mixed approach is problematic because it ignores the kind of explicitation that results in generalization. Within the encoded/inferred distinction of meaning, both specification and generalization can be theoretically regarded as a process of explicitation as long as they are derived from the spelling out of recoverable meanings.

Unlike Øverås, Séguinot (1998) suggests that explicitation may not only include shifts from implied meanings, but all kinds of additions in general and any other change that makes the text clearer in the target language. Compared to Øverås, this standpoint is an even more expanded version of Blum-Kulka's concept and is one that lends itself to a target-text oriented explicitation. Following Blum-Kulka, Séguinot also argues that explicitation should refer to "additions in a translated text which cannot be explained by structural, stylistic, or rhetorical differences between the two languages" (1998, p. 108).

After Øverås (1998) and Séguinot (1998), another group of scholars, including Olohan and Baker (2000), Puurtinen (2004), and Pápai (2004), attempted to prove Blum-Kulka's explicitation hypothesis by investigating a much larger body of data in the form of comparable corpora. This method measures the shifts of explicitation in a corpus of translated texts in a particular language by comparing them with a corpus of non-translated texts of the same genre in the same language.

Unlike Blum-Kulka, Olohan and Baker (2000) include the traditional notion of explicitation in their definition, i.e. the spelling out of information which is otherwise implicit in the ST. They see explicitation as "extra information", a formulation which closely echoes Vinay and Darbelnet's view of "gain of information" (1995, p. 170). Yet they follow the translated version of the concept by defining explicitation as "the spelling out of information which is otherwise implicit in the source language" (2000, p. 142). This standpoint is somewhat contradictory since the latter type of explicitation (the 
traditional type $)^{5}$ may not necessarily result in extra information. In spite of this, because Olohan and Baker work in a syntactic context, i.e. the spelling out of the English particle 'that', the position can still be justified. Every shift will result in a gain: in such cases the shifts come from zero encoding of the connective. This would be different in cases that include substitutions since these may result in more general information, which does not lead to increased informativity. Because of this, Olohan and Baker's view is problematic if applied to expanded categories of explicitation.

Another problem with their study is the use of comparable corpora in explicitation research. This method has been criticized as working against the relational nature of explicitation (see Hansen-Schirra et al., 2007), as the compiled translated and non-translated texts are not necessarily related to each other. Heltai (2005) argues that such a method would yield a different type of phenomenon. Referring to Chesterman's categories of universals (2004), Heltai argues the type of universal should be addressed in explicitation research in order to avoid confusion. Chesterman proposes a distinction between 'S-universals' and 'T-universals' in the quest for translation universals through the "descriptive route" $(2004$, p. 39). S-universals refer to "universal differences between translations and their source texts". In this way, they are concerned with how translators process the source text. Tuniversals, on the other hand, refer to "universal differences between translations and comparable non-translation texts" (p. 39) and explain the way translators use the TL.

Despite the issue Heltai has pointed out, the use of comparable corpora in the study of explicitation has its merits and followers. Puurtinen (2004), for instance, conducted a similar project on connectives in translated and nontranslated Finnish children's literature. Unlike Olohan and Baker (2000), Puurtinen (2004, p. 165) focuses on "a higher degree of explicitness in translated texts than in non-translated texts in the same target language", which according to her reflects Chesterman's (2004) concept of 'Tuniversals'.

Another study using the comparable corpora method was conducted by Pápai (2004), who investigated English into Hungarian translation texts. The scholar, however, only uses the data as a tool to "confirm" findings from the parallel corpora she also employs. Furthermore, she differentiates between 'process-' and 'product-' oriented explicitations (2004, p. 145), two terms which are also used by Englund Dimitrova (2005) but with different meanings. According to Pápai (2004, p.145), as a process explicitation is "a translation technique", while as a product, it refers to "a text feature" in the target text. Unlike Blum-Kulka (1986/2000), Pápai's explicitation includes shifts to cater to different audiences.

As Pápai relies much on formal features (including punctuation marks), her concept of explicitness is somewhat superficial. She believes "translations from English into Hungarian would be expected to result in implicitation" because the latter is agglutinative and "uses fewer words for the same meaning in [...] English" (Pápai, 2004, p. 159), which is not necessarily true (see also Becher, 2010b). Although most of the studies tending to follow Blum-Kulka (Olohan \& Baker, 2000; Øverås 1998, Pápai, 2004; Séguinot, 1998) claim to confirm her hypothesis, Becher (2010b) argues their findings are biased because they fail to filter their data from shifts that may result from differences between SL's and TL's stylistic norms (e.g. Øverås, 1998; Pápai, 2004). According to Blum-Kulka, it is paramount to conduct a comprehensive contrastive stylistic study to validate her hypothesis because her concept of

\footnotetext{
${ }^{5}$ This explicitation concept is based on the distinction of encoded/inferred meaning levels. 
explicitation is independent of the linguistic characteristics of the languages involved in the translation. Becher (2010b) also insists many of them do not provide a clear concept of explicitation and its operation either. As a result, Becher points out that the studies cannot be considered to have validated the explicitation hypothesis.

While Becher's proposal (2010b) is appealing, his understanding of Blum-Kulka does not seem to be accurate. One problem is that Blum-Kulka's 'explicitation' is drawn from discoursal patterns of cohesion and coherence. In order to get the pattern of the translated texts, she includes all shifts due to stylistic preference, including those that may be influenced by SL/TL features. This pattern is then compared with patterns of both SL and TL non-translated texts to determine if explicitation has occurred. With this in mind, Øverås (1998) and Pápai (2004) have closely followed Blum-Kulka's framework by including all stylistic shifts in their data because they subsequently check their findings against information on the corresponding SL/TL stylistic preferences.

Øverås's (1998) study, however, is restricted because it only uses information on language pair stylistic preferences from informants to check her findings, which she herself acknowledges is a limitation of her study. Pápai's study (2004), on the other hand, is problematic because she has also included shifts related to "culture-specific items" for different readership (p. 155), which in Blum-Kulka's (1986/2000) view does not qualify for explicitation shifts. However, since Pápai counts each item separately, her findings on her cohesive items cannot be disqualified either. ${ }^{6}$

Thus, many of the studies cannot be considered to confirm Blum-Kulka's hypothesis because they use comparable corpora, which are non-bidirectional and, as Heltai (2005) points out, will produce a different phenomenon (Tuniversals). It is also difficult to conceive that the use of such corpora can validate an increase of explicitness resulting from translation per se because there may be different factors involved in the production of the translation corpus. On the other hand, studies using parallel texts such as Øverås's (1998) and Pápai's (2004) can still be treated as a preliminary indication supporting Blum-Kulka's prediction, despite their limited validity. Apart from this, the author agrees with Becher (2010b) on the need for conceptual clarity for explicitation research, since all the aforementioned validity issues are due in part to a lack of attention to this issue. As mentioned earlier, this may also cause problems when the linguistic items in focus are expanded to cover grey areas in terms of explicitness (based on meaning levels, textual, or both).

\section{Attempt at unification and the asymmetry hypothesis}

Klaudy and Károly (2005) tried to bring the various approaches to explicitation together under a single concept, including the encoded/inferred and textual approaches to explicitation. They also considered the shift of formal/structural features that puts more focus on parts of the target language text. Unlike the previously discussed studies, Klaudy and Károly (2005) also investigated implicitation, which they believe to occur, for example, by generalization and combination of several SL words into one TL word.

In addition to the combined typology, they also proposed the 'asymmetry hypothesis', in which explicitation in one direction is not counterbalanced by

\footnotetext{
${ }^{6}$ In spite of this, Pápai's use of item frequencies to confirm findings might be an issue if the patterns of the items in focus go beyond the number of occurrences at the discourse level, but the author is unable to comment on this since they do not understand Hungarian.
} 
implicitation in the opposite direction (Klaudy, 2004; Klaudy \& Károly, 2005). According to them, such an approach can be used to validate that explicitation is a translation universal (Klaudy \& Károly, 2005). In favor of the hypothesis, Becher (2010a) also suggests that it may be used as an alternative to Blum-Kulka's Explicitation Hypothesis.

While the asymmetry hypothesis is a crucial suggestion to explicitation research, Klaudy and Károly's combined typology is problematic. As discussed earlier, while generalization is associated with implicitation under textual explicitness, it may be seen as explicitation under the encoded/inferred system. This shows that the current conceptual system of explicitation/implicitation does not support the categories normally employed for the description of the shifts. Would this problem remain if we were to conceptualize the explicit/implicit distinction differently for the process of explicitation/implicitation?

\section{Alternative frameworks to explicitation}

\subsection{Explicitation/implicitation as prototypes}

Kamenická (2007) sees explicitation and implicitation as processes and differentiates them from addition/omission by the retrievability of the information involved in such shifts. However, it is sometimes difficult to be sure of the borders between the two pairs of categories. Using Fillmore's (1982) concept of 'frame', Kamenická (2007, p. 55) proposes that explicitation/implicitation shifts be seen as "prototypes" on a scale, with a centre and periphery. The centre will include cases that easily lend themselves to explicitation/implicitation, while the periphery will include shifts of explicitation in which the recoverability of the specific meaning involved is less likely. While her proposal seems plausible, Kamenická's examples are still limited. She does not cover how more complex renderings of figurative expressions may be explained in terms of her categories. In addition, as the encoded/inferred concepts are used to differentiate between explicitation and implicitation, the framework cannot distinguish shifts from more refined levels of meaning interpretation.

In addition to the prototype-based classification, Kamenická (2008) proposes another typology which is based on Hallidayan metafunctions of language: experiential, logical, interpersonal and textual. She argues that such an approach may explain the different aspects of the pragmatic situation that motivate explicitation shifts and can serve as an alternative to Klaudy's typology, which is more interested in the SL/TL systemic differences. Unfortunately, she provides hardly any explanation on how each of her categorizations operates except for two examples of interpersonal explicitations (see also Becher, 2010b). While this is a potential framework, explaining the grey areas of explicitness and implicitness is still necessary and can only be done by taking the cognitive nature of meaning interpretation in communication into account.

\subsection{Explicitation based on audience design}

Saldanha (2007) has suggested that explicitation should be viewed in terms of audience design rather than in terms of its link to implicit meanings because explicitation is not necessarily related to the recovery of implicit information. She proposes that explicitation is "a translation strategy whereby translators spell out optional interpersonal, ideational or textual meanings in the target text" (2008, p.32). This strategy takes into account the cognitive store of the 
reader and the translator's decisions, neither of which are necessarily related to the source text.

In the author's view, although the reader is a very important factor in explicitation, he/she may not be the main variable motivating the translator to spell out meanings. Explicitation is also a function of norms, such that the use of the strategy is also determined by contemporary perceptions about translation itself (Weissbrod, 1992). Of course, the norms may not necessarily depend on the audience. They may come from the dominant literary community of the target language or even from the translators themselves by reflecting their personal styles. Given these additional considerations, seeing explicitation only in terms of audience design does not seem to be the best option.

\subsection{Explicitation based on processability}

Heltai (2005) suggests the need for explicitation research to further examine the notion of explicitness as meaning processability rather than just focusing on linguistic explicitness. Linguistic explicitness in Heltai's point of view is textual explicitness, which is indicated by the presence of more linguistic forms. Such explicitness is inadequate for the basis of explicitation because explicitation is normally associated with its "psycholinguistic consequences" (n.p.). Here Heltai believes that "true explicitness lies in less ambiguity and easier processing". Accordingly, he points out, "It]rulyexplicit utterances are coded in the linguistic form ensuring the most unambiguous interpretation of an utterance or text in a given situation" (original bolding, 2005, n.p.). Greater linguistic explicitness does not always lead to ease of comprehension. Unlike linguistic explicitness, explicitness as processability refers to "linguistic coding promoting easier comprehension" (n.p). Hence, explicitation is a shift to resolve ambiguity and easier processing (n.p).

Heltai's concept of processability in explicitation is similar to Schiffrin's (1994/2003) idea of explicitness, which is based on ease of comprehension and can be very relative depending on the reader. Like explicitness based on audience design, the high relativity of this processability approach would make it impractical as a basis for explicitation, as perceptions of a text in the target audience are bound to vary. In spite of this, Heltai offers insightful observations pertinent to the study of the phenomenon. One of these is on how the addition of linguistic forms does not necessarily contribute to explicitness as processability. The Hungarian sentence Kék a szeme contains fewer morphemes than its English equivalent Her eyes are blue and does not indicate the plural number of the eyes. In terms of linguistic explicitness, the Hungarian sentence is therefore less explicit and less processable than the English one. In Heltai's view (2005, n.p), this is of course "counter-intuitive" under the concept of explicitness as processability. Besides demonstrating that explicitation research should go beyond linguistic differences between SL and TL, again, the above discussion also suggests that it needs a coherent framework to explain the complexity of explicitness in meaning interpretation. Pragmatic theories are one option that may explain cases such as why Her eyes are blue does not seem to be more processable than Kék a szeme. Under Grice's (1975) view, for instance, the plural information in the Hungarian version can only be recovered by inference. The utterance would still share the same "what is said" with the English sentence. The relevance theory goes further with this view by categorizing such inferable information into the explicit. This is based on the thesis of under-determinacy, which sees languages as too weak to be capable of encoding all the humanly possible thoughts. Hence what is encoded in linguistic symbols cannot fully represent what is in someone's mind. In other words, our thoughts can never be fully 
explicit in what we say and consequently communication always involves some element of inference. Because of this, Sperber and Wilson believe that the encoded/inferred concept cannot be used as a criterion to differentiate between the explicit and implicit (1986). Their theory is used as the basis of the author's explicitation/implicitation framework, which shall be briefly addressed in the following section.

\section{Explicitation/implicitation framework based on the Relevance Theory}

Unlike earlier frameworks of explicitation/implicitation, this framework (Murtisari, 2011, 2013) is based on a cognitive theory of communication that comprehensively deals with the concepts of 'explicit' and 'implicit'. To represent the 'explicit' and the 'implicit', the relevance theory (RT) creates a division between 'explicature' and 'implicature', which are elaborated on the basis of Grice's "what is said" and "conversational implicature" (Grice, 1975).

Explicature, which is never fully explicit, covers the area of meaning resulting from the development of an utterance's logical form ${ }^{7}$. The interpretation of an explicature is based on the decoding of linguistic forms and pragmatic inference. Different utterances may have the same explicatures, but with a different degree of explicitness (Carston, 2002, p.117). As an example, the utterances (a) The dog is in the yard, (b) The dog is there, and (c) It is there share the same explicature. However, (a) is the most explicit, and (b) is more explicit than (c). They also have different pragmatic effects.

Implicatures, on the other hand, are implications that are derived purely from contextually-based inferences. Hence, these are also referred to as contextual implications. When one says (a) I am busy to mean (b) I cannot help you, then (b) is an implicature of the utterance (a). An implicature may be strong or weak, depending on the context.

Drawing on the distinction between 'explicature' and 'implicature', the author has proposed a typology of scalar/categorical explicitation and deexplicitation to refine the conventional notions of explicitation/implicitation. The scalar shifts refer to shifts within the explicature, whose explicitness is a matter of degree. The categorical shifts, on the other hand, refer to those involving a change of category in meaning, i.e. from the explicature to the implicature and vice versa. It is worth noting that the author has suggested the term 'deexplicitation' (hereinafter written with a hyphen - "de-explicitation"to facilitate reading) to refer to the more generic shifts to a less explicit degree of meaning. Although the term 'implicitation' is still used as another name for categorical de-explicitation (shifts to the implicature) within this relevancebased framework, it cannot be used to refer to shifts within the explicature as this area is inherently explicit. Hence, while such shifts may lead to lower explicitness, the resulting form will still be explicit.

It is important to note that the scalar/categorical typology can only be employed to analyze bi-directional texts despite its ability to cover a combined notion of explicitness (meaning levels, ease of processability, and textual/linguistic explicitness). Deciding whether a shift is scalar or categorical must be based on the context of communication. Consequently, the scalar/categorical differentiation is not applicable for studies using comparable non-translation corpora or those using parallel corpora without looking at the shift from ST to TT. Shifts of meanings that are not related to the ST or that are purely based on textual/linguistic explicitness or encodedness (number of

\footnotetext{
${ }^{7} \mathrm{~A}$ logical form is "a syntactically structured string of concepts with some slots of free variables, indicating where certain contextual values (in the form of concepts) must be supplied" (Carston, 2002, p. 64).
} 
morphemes and/or typographical markers) are instead treated as a separate category of explicitation/de-explicitation.

Unlike in the previous framework, generalizations/specifications may be consistently integrated within the relevance-based system. A decrease in informativity and generalization (within explicature) will always result in deexplicitation, while the reverse leads to explicitation. On the other hand, deductive generalizations and specifications which are not a development of the ST logical form are considered categorical explicitations because the explicitness is assessed from the change of meaning level (Murtisari, 2011, 2013).

Although the framework is based on a comprehensive research of theories of meaning interpretation, it is still preliminary. More work is needed to test its applicability in different contexts of meaning shifts and improve the framework while taking into account more research on 'implicitation'. Another aspect that is worth noting is the framework's use of the entirely unfamiliar term 'de-explicitation'. Arguing that the term is a misnomer ("[sic!]"), Krüger considers that the framework undermines 'implicitation' and he raises his strong objection to the coinage $(2015$, p. 224, footnote). Such objection is understandable because 'implicitation' is already an established term, but the typology is still open for improvement and the term may later be changed if a better option arises. Regardless of this issue, openness to change is necessary if we are to better describe explicitation/implicitation because the conventional encoded/inferred distinction for explicitness/implicitness cannot satisfactorily explain the phenomenon.

\section{Conclusion}

This research demonstrates that while explicitation is a complex notion, many studies of it as a phenomenon fail to provide an adequate explanation of it as a concept. The lack of attention to the conceptual issue has often lead to methodological choices which limit the validity of the studies' claims or even nullify them. This is especially true with the use of comparable corpora for validating Blum-Kulka's prediction. Although the latter is a useful method for studies on target-text oriented features of translations as compared to nontranslated texts, the corpora cannot be used to prove a hypothesis resulting from the translation process per se.

Some scholars have proposed new approaches to better explain explicitation (and implicitation) but most are still restricted to partial aspects of explicitness/implicitness. A comprehensive account of meaning interpretation in human communication is required to develop a sound framework of explicitation and its grey areas. On the other hand, although an attempt has been made to explain explicitation (and implicitation) in light of a coherent theory of meaning in communication (Murtisari, 2011, 2013), the framework still needs to be tested. Far more research needs to be conducted to establish a comprehensive and systematic framework for studies on explicitation, which is crucial to study this phenomenon as a possible translation "universal". Even if explicitation does not prove to be a universal feature, it is unarguably a pervasive one, and such a framework is still paramount in creating common ground for more comparable studies into it. This will pave the way for establishing more significant generalizations about it, which in turn will help us to better understand how translation operates as a specific type of interlingual communication. Translator training will benefit most from such findings - first and foremost, because they will help trainees to become aware of tendencies in translation that draw on adequate 
understanding of the nature of meaning interpretation, and to critically deal with them as they develop their own strategies for negotiating meaning between ST and TT. Thus, more than just exploring mere theory, there are overwhelmingly practical benefits to be gained by moving beyond the current, almost chaotic, conceptual landscape in which explicitation is presently situated.

\section{References}

Ädel, A. (2006). Metadiscourse in L1 and L2 English. Amsterdam \& Philadelphia: John Benjamins.

Becher, V. (2010a). Abandoning the notion of "translation-inherent" explicitation. Against a dogma of translation studies. Across Languages and Cultures, 11(1), $1-28$.

Becher, V. (2010b). Towards a more rigorous treatment of the Explicitation Hypothesis in translation studies. Trans-kom, 3(1), 1-25.

Blum-Kulka, S. (2000). Shifts of cohesion and coherence in translation. In L. Venuti (Ed.), The translation studies reader (pp. 298-312). London \& New York: Routledge. (First published 1986 in J. House \& S. Blum-Kulka (Eds.), Intercultural communication: Discourse and cognition in translation and second language acquisition (pp. 17-35). Tübingen: Narr).

Carston, R. (2002). Thoughts and utterances: The pragmatics of explicit communication $\left(2^{\text {nd }}\right.$ ed.). Oxford \& Malden: Wiley-Blackwell.

Chesterman, A. (2004). Beyond the particular. In A. Mauranen \& P. Kujamäki (Eds.), Translation universals: Do they exist? (pp.33-50). Amsterdam \& Philadelphia: John Benjamins Publishing.

Englund Dimitrova, B. (2005). Expertise and explicitation in the translation process. Amsterdam \& Philadelpia: John Benjamins Publishing.

Frankenberg-Garcia, A. (2004, January). Are translations longer than source texts? A corpus-based study of explicitation. Paper presented to the Third International Corpus Use and Learning to Translate Conference, Barcelona. Retrieved from http:/www.linguateca.pt/Repositorio/Frankenberg-Garcia2004.d0c.

Grice, H. P. (1975). Logic and conversation. In D. Davidson \& G. Harman (Eds.), The Logic of Grammar (pp. 64-75). Encino, CA: Dickenson. Original paper presented in the William James Lectures, Harvard University, 1967.

Hansen-Schirra, S., Neumann, S., \& Steiner, E. (2007). Cohesive explicitness and explicitation in an English-German translation corpus. Languages in Contrast, $7(2), 241-66$.

Heltai, P. (2005). Explicitation, redundancy, ellipsis and translation. In K. Károly \& Á. Fóris (Eds.), New trends in translation studies (pp. 45-74). Budapest: Akadémiai Kiadó.

Kamenická, R. (2007). Defining explicitation in translation. Brno Studies in English 33(1), 45-57. Retrieved from http://www.phil.muni.cz/plonedata/wkaa/BSE/BSE _2007-33_Offprints/BSE\%202007-33\%20(045-057)\%20Kamenická.pdf

Kamenická, R. (2008). Explicitation profile and translator style. Retrieved from http://isg.urv.es/library/papers/KamenickaExplicitation.pdf

Klaudy, K. (1998). Explicitation. In M. Baker \& G. Saldhana (Eds.), Encyclopaedia of Translation Studies (pp. 80-85). London: Routledge.

Klaudy, K. (2004). The asymmetry hypothesis: Testing the asymmetric relationship between explicitations and implicitations. In G. Hansen, K. Malmkjær, \& D. Gile (Eds.), Claims, changes and challenges in translation studies: Selected contributions from the EST Congress, Copenhagen. Amsterdam: John Benjamins Publishing Company.

Klaudy, K., \& Károly, K. (2005). Implicitation in translation: Empirical evidence for operational asymmetry in translation. Across Languages and Cultures, 6(1), 1328.

Krüger, R. (2015). The interface between scientific and technical translation studies and cognitive linguistics. Berlin: Frank Timme. 
Murtisari, E.T. (2011). The uses of relevance theory for the study of explicitation (Unpublished doctoral dissertation). Monash University, Melbourne, Australia.

Murtisari, E. T. (2013). A relevance-based framework for explicitation and implicitation: An alternative typology. Trans-kom, 6(2), 315-344.

Nida, E. (1964). Toward a science of translating: With special reference to principles and procedures involved in Bible translating. Leiden: E.J. Brill.

Olohan, M., \& Baker, M. (2000). Reporting that in translated English: Evidence for subconscious processes of explicitation? Across Languages and Cultures, 1(2), 141-158.

Øverås, L. (1998). In search of the third code: An investigation of norms in literary translation. Meta, 43(4). Retrieved from https://www.erudit.org/revue/meta/199 8/v43/n4/003775ar.html

Pápai, V. (2004). Explicitation: A universal of translation text? In A. Mauranen \& P. Kujamäki (Eds), Translation universals: Do they exist? (pp.143-64). Amsterdam \& Philadelphia: John Benjamins.

Puurtinen, T. (2004). Explicitation of clausal relations: A corpus-based analysis of clause. Connectives in translated and non-translated Finnish children's literature. In A. Mauranen \& P. Kujamäki (Eds), Translation universals: Do they exist? (pp.165-76). Amsterdam \& Philadelphia: John Benjamins.

Saldanha, G. (2008). Explicitation revisited: Bringing the reader into the picture. Trans-kom, 1(1), 20-35.

Schiffrin, D. (1994). Approaches to discourse. Cambridge, Massachusetts: Blackwell Publishers.

Séguinot, C. (1988). Pragmatics and explicitation hypothesis. TTR: Traduction, Terminologie, Rédaction, 1(2),106-14.

Sperber, D., \& Wilson, D. (1986). Relevance: communication and cognition. Oxford: Blackwell

Vinay, J., \& Darbelnet, J. (1958). Stylistique comparée du français et de l'anglais. Paris: Didier.

Vinay, J., \& Darbelnet, Jean. (1995). Comparative stylistics of French and English: A methodology for translation. (J.C. Sager \& M.-J. Hamel, Trans). Amsterdam \& Philadelpia: John Benjamins. (Original work published in 1958).

Weissbrod, R. (1992). Explicitation in translations of prose-fictions from English to Hebrew as a function of norms. Multilingua, 11(2), 153-71.

Wilson, P. (2014). Mind the gap: Ellipsis and stylistic variation in spoken and written English. London: Routledge. 